\title{
O gênero da antropologia
}

\section{The gender of anthropology}

\author{
Mariana Françozo \\ Doutoranda em ciências sociais \\ Instituto de Filosofia e Ciências Humanas, Unicamp \\ Rua Aristides Lobo, 83 \\ 13083-060 Campinas - SP Brasil \\ mariana_f@terra.com.br
}

"Também é ser, deixar de ser assim"

Cecilia Meireles

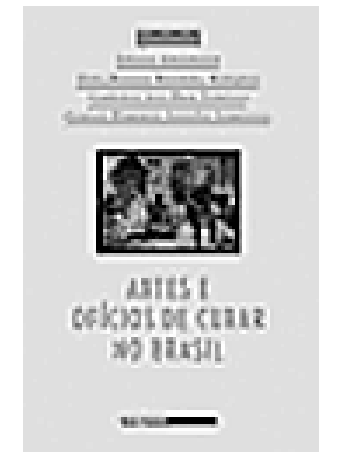

Mariza Corrêa Antropólogas e antropologia Belo Horizonte, Ed. UFMG, 2003. 278 p.
$\mathrm{H}$ á pouco mais de vinte anos, a antropologia brasileira se debruça sobre um objeto tão instigante quanto desafiador: sua própria história. Instigante, porque permite descobrir fatos e personagens às vezes totalmente desconhecidos, que não só iluminam aspectos do desenvolvimento da disciplina mas também lançam luz sobre a prática antropológica atual. Desafiador, porque requer do pesquisador um bom faro para seguir pistas fornecidas, no mais das vezes, por referências vagas e lembranças incertas, em dedicatórias e agradecimentos de livros, notas de rodapé, fotografias, ou arquivos pessoais e institucionais.

Mariza Corrêa enfrenta esta difícil e reveladora tarefa em seu mais recente livro, a coletânea de artigos Antropólogas e antropologia. Inserindo a pesquisa histórica no debate sobre gênero, a autora oferece uma consistente interpretação sobre a atuação das mulheres no campo da antropologia entre o final do século XIX e as cinco primeiras décadas do século XX, bem como sobre os efeitos de tal atuação.

A pesquisadora elege três figuras femininas que trabalharam na área da antropologia naquele período e, seguindo suas trajetórias, mostra as implicações e as reações que suas práticas despertavam em seus pares, numa disciplina então eminentemente masculina. Deste modo, Mariza Corrêa elucida como estas mulheres foram vistas e representadas naquele meio, isto é, revela e analisa o lugar que lhes foi atribuído, uma vez que a presença feminina na profissão ainda não podia ser facilmente aceita.

Não se trata, assim, de três biografias de mulheres excepcionais, tampouco de uma denúncia das dificuldades por elas enfrentadas ao longo de suas carreiras. Antes, estas três vidas - com seus sucessos e percalços - servem para a autora compreender "como certas figuras tão preeminentes na nossa tradição (...) foram apreendidas quando conjugadas no feminino." (p. 16) Temos portanto uma análise das categorias de identidade acionadas no campo antropológico daquela metade de século, entendidas primeiramente através da dualidade ho$\mathrm{mem} / \mathrm{mulher}$. Pode-se dizer, neste sentido, que um dos méritos deste livro é contar a história de nossa antropologia sem fazer desta um arrolado de acusações e denúncias ou um elogio mitificante das vidas de alguns sujeitos. $\mathrm{O}$ interesse central da autora é, através destas vi- 
das, pensar como eram entendias e vivenciadas as relações de gênero entre os praticantes da antropologia no Brasil daquele tempo.

As personagens de Mariza Corrêa, por ordem de aparecimento no livro, são Emilia Snethlage, ornitóloga alemã que veio ao Brasil em 1905 e trabalhou como pesquisadora no Museu Goeldi e no Museu Nacional; Leolinda Daltro, sertanista que, a partir de fins do século XIX, atuou junto aos índios para "civilizá-los"; e Heloisa Alberto Torres, que trabalhou por quase trinta anos no Museu Nacional e empenhou-se na formação de jovens pesquisadores e no incentivo à pesquisa de campo.

Estas mulheres desafiavam a tradicional dualidade homem/mulher, uma vez que desempenhavam as mesmas atividades que seus pares masculinos num campo por eles dominado. Assim, embaçavam as fronteiras entre ser homem e ser mulher, e colocavam em xeque as definições de masculino e feminino. Por este motivo, suas trajetórias são de particular interesse para o estudo das relações de gênero. Vamos então a estas mulheres e suas histórias.

Para entendê-las, Mariza Corrêa, no primeiro artigo, parte de três romances em que tais mulheres surgem como personagens. Em 1915, Leolinda Daltro aparece no romance Numa e a Ninfa, de Lima Barreto; Heloisa Alberto Torres, em 1933, é retratada no romance No Pacoval de Carimbé, de Bastos de Ávila; e em 1938 Emilia Snethlage aparece em Os Igaraúnas, de Raimundo de Morais. Neles são caracterizadas respectivamente como uma mulher que faz "aventuras com os caboclos"; como uma professora que mais parece, segundo Corrêa, uma "Indiana Jones de saias." (p. 67); e, finalmente, como uma cientista estrangeira que se aventura pela floresta amazônica.

Mariza Corrêa mostra como, no romance de Lima Barreto, Leolinda está representada de forma grotesca, com insinuações maliciosas sobre sua relação com os índios, explicitando quão incômoda era a atuação das mulheres na esfera política e pública no começo do século XX. No caso do livro de Ávila, Heloisa Alberto Torres é retratada como modelo de profissional de pesquisa, mas sua atuação discreta como pesquisadora valida de modo ambíguo sua inserção num mundo profissional masculino. Já no romance de Morais, a ligação de Emilia Snethlage com a ciência - esfera masculina - é mais claramente destacada; ainda assim, ela é vista antes de tudo segundo a típica imagem da mulher, e é descrita a partir de seus atributos femininos mesmo em seus afazeres científicos.

O recurso aos romances para pensar figuras da antropologia serve como bom exemplo da possibilidade de aproximarmos, para fins de pesquisa, antropologia e literatura. Evidentemente, são dois campos distintos e que guardam particularidades intransponíveis. No entanto, quando nos debruçamos sobre a literatura e a tomamos como material expressivo para investigar o pensamento de um autor ou de uma época, ou para examinar aspectos da vida social num certo tempo e num certo espaço, ganhamos em amplitude e profundidade. Se não para isso, a literatura interessa, no mínimo, para que tenhamos insights criativos sobre o que pode ter acontecido com pessoas cujo passado mal conhecemos. Este é o caso do romance Nove noites, de Bernardo 
Carvalho (2002), inspirado aliás em um artigo da mesma Mariza Corrêa.

Terminada a parte mais "ficcional" da análise, a autora aborda as trajetórias das três mulheres. Começa então com a de Emilia Snethlage.

A trajetória desta pesquisadora, como mostra Corrêa, só pode ser entendida no contexto do interesse dos cientistas europeus pelo naturalismo e a conseqüente expansão dos estudos deste tipo feitos no Brasil. Durante a assim chamada 'era dos museus', Emilia estava inserida no grupo de pesquisadores alemães que viajaram à América do Sul em busca de espécies novas para as coleções das instituições para as quais trabalhavam. Havia, entretanto, algo que a tornava singular aos olhos dos antropólogos brasileiros: ela era uma mulher que, sozinha, fazia expedições em busca de seus objetos de estudo.

Segundo a autora, o fato de Emilia ser estrangeira parecia valer como explicação para seus atos tão pouco femininos, como se aventurar sozinha pelo interior. Em discursos feitos (por homens) em sua homenagem, afirmava-se que ela tinha um 'espírito varonil', mas ao mesmo tempo acentuava-se seus aspectos 'femininos': o "cabelo à moda antiga", o "chapéu severo das senhoras de idade". Emilia era vista de forma ambígua, pois suas ações se enquadravam às vezes na esfera do masculino, às vezes na do feminino. De qualquer modo, fica claro que a questão posta era a presença - e o sucesso - de uma mulher numa profissão masculina. Isso fica anedoticamente evidente no curioso episódio em que, tendo recebido uma carta endereçada ao "sr. Emilio Snethlage", a ornitóloga exclama: "Isso convenceu-me de que havia feito o trabalho de um homem" (p. 102).

Leolinda Daltro causou maiores controvérsias, tendo sido, com efeito, alvo de perseguições diretas em virtude de sua atuação política. Seu empenho em 'civilizar' os índios era alvo de chacota e, quando trocou a militância em favor dos índios pela luta em prol do voto feminino, também foi ridicularizada. Mariza Corrêa se detém na primeira destas militâncias e reconstrói o percurso de Leolinda através de cartas, notícias de jornal e textos deixados pela própria sertanista. Deste modo, vai revelando, por trás de cada episódio, as idéias então vigentes sobre o lugar do homem, o lugar da mulher, o espaço dos índios e o das sufragistas na vida social e política do país.

Através da trajetória de Leolinda observa-se que o movimento indígena em busca de reconhecimento e representação política não é um fenômeno recente, pois os índios, desde aquele começo de século, estavam preocupados em se organizar e reivindicar seus direitos políticos. Esta constatação é um bom exemplo de como o objeto e o material escolhidos por Mariza Corrêa para estudar o gênero na história da antropologia nos ajudam a situar com mais precisão o debate antropológico contemporâneo.

Talvez a mais conhecida das três antropólogas, Heloisa Alberto Torres teve um papel fundamental não só na consolidação do Museu Nacional como um dos centros da antropologia brasileira, como também na constituição da pesquisa antropológica como hoje a conhecemos. O estudo que Mariza Corrêa faz de sua trajetória é informativo, pois retoma o contexto e a história de instituições do campo antropoló- 
gico de então, como o Museu Nacional, a Faculdade Nacional de Filosofia do Distrito Federal, e até a fundação da ABA.

Este estudo nos permite levantar dois pontos importantes. O primeiro, que fica evidenciado na disputa entre Heloisa Alberto Torres e os naturalistas do Museu Nacional pela direção desta instituição, refere-se ao já mencionado problema do lugar do feminino e do masculino neste campo da ciência. Ao reconstituir esta disputa, Mariza Corrêa evidencia que o que estava em questão era menos a qualificação de cada um para ocupar tal cargo do que "a poluição das fronteiras sociais entre o masculino e o feminino" (p.152) suscitada pela presença de Heloisa como diretora. A mesma questão estava presente quando Heloisa competiu com Arthur Ramos pela cátedra de Antropologia e Etnografia na Universidade do Distrito Federal.

O segundo ponto, ao qual a autora se refere já na introdução do livro, é a questão do 'nome'. Heloisa herdara o nome do pai - o político e intelectual Alberto Torres - e isso lhe garantia um lugar diferente na disciplina. Muito longe de ter o mesmo status dos homens, Heloisa, entretanto, não era mal-vista nem tão abertamente criticada como Emilia e Leolinda. Ela tinha seu prestígio e estava autorizada a circular e acionar "uma ampla rede social" (p. 143) em favor de seus projetos. Por sua vez, as antropólogas que não contavam com o nome do pai ou do marido como suporte e justificativa para sua presença no campo não compartilhavam das mesmas possibilidades.

O desconforto criado pela presença de uma mulher que não era 'filha de' nem 'esposa de' reaparece no quinto artigo do livro, em que a autora examina partes da carreira da antropóloga norte-americana Ruth Landes. Essa pesquisadora esteve no Brasil no final da década de 1930 para estudar o candomblé da Bahia. Sua presença despertava vários incômodos, especialmente no antropólogo brasileiro Arthur Ramos. Ela era uma mulher, sozinha, entrando num campo dominado por homens; teve uma parceria amorosa e intelectual com o pesquisador negro Édison Carneiro; focou seu trabalho na perspectiva da raça e não da cultura; e mostrou a importância das mulheres e dos homossexuais nas religiões afro-brasileiras. Estes foram motivos suficientes para que ela sofresse uma dura perseguição tanto no Brasil quanto nos Estados Unidos - por parte de Melville Herskovits -, o que acabou por minar muitas de suas possibilidades profissionais.

O caso de Ruth Landes mostra a complexidade da questão posta por Mariza Corrêa, pois além do gênero, também a raça é fator de diferenciação no meio antropológico. Explorando a atuação e a perseguição de Ruth Landes, bem como sua associação com Heloisa Alberto Torres e os conflitos de ambas com Arthur Ramos, a autora explicita os embates políticos entre antropólogos que buscavam legitimar sua prática e seu campo de pesquisa como antropologia 'oficial'.

Mariza Corrêa encerra seu livro com um artigo sobre as linhagens femininas nas tradições antropológicas norte-americana, inglesa e francesa. Demonstra como nestas três 'culturas' antropológicas os significados de feminino e masculino são diferentes, assim como o eram no Brasil do período analisado. Deste modo, fica evidente que nestas tradições, assim como na brasileira, não havia - e não há - um estilo 
feminino e outro masculino de se fazer antropologia. Ao contrário, os estilos existentes "em cada época e no interior de cada tradição eram compartilhados por homens e mulheres" (p. 206).

A contribuição de Mariza Corrêa para a história da antropologia é inegável, tanto nesse livro como em obras precedentes. Contudo, o alcance deste livro vai além das décadas em que viveram Emilia, Leolinda, Heloisa e Ruth, não só porque inclui um capítulo sobre tradições antropológicas até o final do século XX, mas sobretudo porque discute o gênero na história da antropologia a partir de uma questão fundamental da disciplina: se gênero é entendido como uma relação, e se esta é uma relação construída a partir do que tomamos por diferenças, como então construímos a diferença? O que é, afinal, ser outro?

\section{REFERÊNCIAS BIBLIOGRÁFICAS}

Carvalho, Bernardo 2002
Nove noites.

São Paulo: Companhia das Letras.

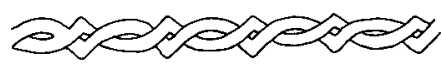




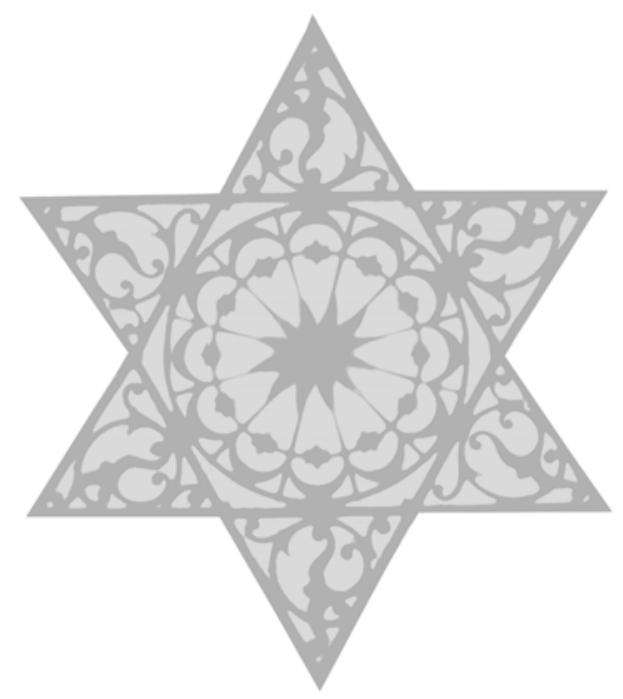

